\title{
Identification of Transcriptionally Active Open Reading Frames within the RD1 Genomic Segment of Mycobacterium tuberculosis
}

\author{
Hanady A. Amoudy Mariam B. Al-Turab Abu S. Mustafa \\ Department of Microbiology, Faculty of Medicine, Kuwait University, Kuwait
}

\author{
Key Words \\ Mycobacterium tuberculosis - Active open reading \\ frames $\cdot$ Reverse transcription-polymerase chain \\ reaction $\cdot$ Gene expression
}

\begin{abstract}
Objective: To identify transcriptionally active open reading frames (ORFs), predicted by bioinformatics, within RD1 genomic segment of Mycobacterium tuberculosis using reverse transcription-polymerase chain reaction (RT-PCR). Materials and Methods: M. tuberculosis H37Rv was grown in Middlebrook 7H9 medium for 8 weeks and total RNA was isolated using standard procedures. The cDNA was synthesized using first-strand cDNA synthesis kit and general primers provided in the kit [pd $(\mathrm{N})_{6}$, and/or Not I-d(T) $)_{18}$ ] as well as forward primers specific for each predicted RD1 ORF. Specific forward and reverse primers in PCR were used to amplify ORFspecific cDNA. The amplified products were identified on the basis of size using agarose gel electrophoresis, and their identity was confirmed by DNA sequencing. $\boldsymbol{R e}$ sults: RT-PCR demonstrated expression of 13 of the 14 bioinformatics-predicted ORFs within RD1 genomic segment of $M$. tuberculosis. However, cDNA synthesis and PCR amplifications of specific products varied with respect to primer requirement and reaction conditions, respectively. All ORFs of $<1.5 \mathrm{~kb}$ were amplified in standard RT-PCR, whereas several large-size ORFs (>1.5 kb)
\end{abstract}

required internal primers for amplification in semi-nested RT-PCR. The sequencing of RT-PCR-amplified products of ORFs confirmed their identity. Conclusion: Bioinformatics analysis of DNA can accurately predict ORFs within $M$. tuberculosis-specific genomic regions, and RT$\mathrm{PCR}$ is a suitable technique to confirm their expression in bacteria.

Copyright (C) 2006 S. Karger AG, Basel

\section{Introduction}

Tuberculosis (TB) is a major health problem of global concern. The immunological diagnosis of TB requires the identification of antigens specific for Mycobacterium tuberculosis, the causative agent of TB. However, most of the studies conducted in the past to characterize antigens of $M$. tuberculosis were focused on antigens shared between $M$. tuberculosis and other mycobacteria [1-3]. The situation changed in 1996 when Mahairas et al. [4]. opened a new area of study dealing with antigens encoded by $M$. tuberculosis-specific genomic regions deleted in other mycobacteria. They employed subtractive genomic hybridization to identify genetic differences between virulent $M$. tuberculosis and $M$. bovis and the vaccine strains of $M$. bovis BCG. Three distinct genomic regions of $M$. tuberculosis and M. bovis, designated RD1-RD3, were found deleted from the genomes of some or all BCG substrains. RD1, a 9.5-kb DNA segment deleted from all

\section{KARGER}

Fax +4161306 1234

E-Mail karger@karger.ch

www.karger.com
(C) 2006 S. Karger AG, Basel

$1011-7571 / 06 / 0152-0137 \$ 23.50 / 0$

Accessible online at:

www.karger.com/mpp
Dr. Hanady A. Amoudy

Department of Microbiology, Faculty of Medicine, Kuwait University PO Box 24923

Safat 13110 (Kuwait)

Tel. +965 531 2300, ext. 6506, Fax +965 533 2719, E-Mail amoudy@hotmail.com 
Table 1. Annotation and characteristics of the RD1 ORFs of M. tuberculosis deleted in M. bovis BCG

\begin{tabular}{llllll}
\hline \multicolumn{2}{l}{ ORF annotation by } & & $\begin{array}{l}\text { Position } \\
\text { on RD1 }\end{array}$ & $\begin{array}{l}\text { DNA } \\
\text { size, kb }\end{array}$ & Characterization of the protein [12, 17] \\
$\begin{array}{lllll}\text { Mahairas } \\
\text { et al. [4] }\end{array}$ & $\begin{array}{l}\text { Cole } \\
\text { et al. [12] }\end{array}$ & $\begin{array}{l}\text { Robertson } \\
\text { and Thole }\end{array}$ & & \\
\hline ORF1A & Rv3871 & ORF2 & $889-2,664$ & 1.8 & conserved hypothetical protein, function unknown \\
NP & Rv3872 & ORF3 & $2,807-3,103$ & 0.3 & PE family-related protein, function unknown \\
NP & NP & ORF4 & $4,014-3,595 \mathrm{c}$ & 0.4 & hypothetical protein \\
ORF1B & Rv3873 & ORF5 & $3,128-4,243$ & 1.1 & PPE family protein, function unknown \\
NP & Rv3874 & ORF6 & $4,336-4,638$ & 0.3 & CFP10 \\
ORF1C & Rv3875 & ORF7 & $4,671-4,958$ & 0.3 & ESAT-6 \\
NP & NP & ORF8 & $5,502-5,082 \mathrm{c}$ & 0.4 & hypothetical protein \\
ORF1D & Rv3876 & ORF9 & $5,072-7,072$ & 2.0 & conserved hypothetical alanine and proline-rich protein \\
ORF1E & Rv3877 & ORF10 & $6,946-8,604$ & 1.7 & probable conserved transmembrane protein \\
ORF1F & Rv3878 & ORF11 & $8,755-9,597$ & 0.8 & conserved hypothetical alanine-rich protein \\
ORF1G & NP & ORF12 & $9,787-11,478$ & 1.7 & hypothetical protein \\
ORF1K & Rv3879 & ORF13 & $11,895-9,655 \mathrm{c}$ & 2.2 & hypothetical alanine and proline-rich protein \\
NP & NP & ORF14 & $10,577-11,365$ & 0.8 & 30-kDa protein expressed in $M$. tuberculosis \\
NP & NP & ORF15 & $11,731-12,018$ & 0.3 & hypothetical protein \\
\hline
\end{tabular}

$\mathrm{NP}=$ Not predicted.

BCG substrains, was conserved in all virulent laboratory and clinical isolates of $M$. bovis and M. tuberculosis tested. The reintroduction of RD1 into BCG resulted in a protein expression profile almost identical to that of virulent $M$. bovis and M. tuberculosis [4]. The immunological importance of RD1 became obvious when it was shown that ESAT6 and CFP10, two immunodominant proteins useful for diagnostic applications in TB [5-10], are expressed from genes located in RD1 [11].

In their original publication, Mahairas et al. [4] annotated eight potential active open reading frames (ORFs) in the RD1 region. In the genome sequence of $M$. tuberculosis H37Rv, Cole et al. [12] annotated nine ORFs in this region, seven of which matched those identified by Mahairas et al. [4] (table 1). A bioinformatics analysis of RD1 genomic segment using GeneMark software (http:// opal.biology.gatech.edu/GeneMark/) by B. Robertson and J. Thole (Imperial College, University of London, London, UK) [pers. commun.] revealed the potential presence of 20 ORFs in M. tuberculosis, 14 of these ORFs (ORF2-15) were deleted in M. bovis BCG (fig. 1). In addition to covering all ORFs predicted by Mahairas et al. [4] and Cole et al. [12], Robertson and Thole predicted 4 additional ORFs, i.e. ORFs 4, 8, 14 and 15 (table 1). In a previous work, using the techniques of gene cloning and expression, we were able to recombinantly express ORF14 protein in Escherichia coli [13]. Furthermore, we showed that antibodies in sera from TB patients, but not BCG-vaccinated healthy donors, reacted with the recombinant ORF14 protein [13], and anti-ORF14 antibodies reacted with a single protein, at the same molecular size, from the culture filtrate of in vitro grown M. tuberculosis [unpubl. results]. These studies demonstrated that Robertson and Thole correctly predicted additional ORFs in RD1 that were actually expressed in M. tuberculosis, but were neither included in the prediction of Mahairas et al. [4] nor in the genome sequence of $M$. tuberculosis H37Rv [12]. The aim of the present study was to determine, by using reverse transcription-polymerase chain reaction (RT-PCR), if other RD1 ORFs predicted by Robertson and Thole were also expressed in $M$. tuberculosis at the mRNA level.

\section{Materials and Methods}

Growth and Enumeration of M. tuberculosis $H 37 R v$

A single colony of $M$. tuberculosis H37Rv (obtained from Imperial College, University of London, London, UK) was grown to $5 \times 10^{8} \mathrm{CFU} / \mathrm{ml}\left(6-8\right.$ weeks) at $37^{\circ} \mathrm{C}$ in Middlebrook $7 \mathrm{H} 9$ (Difco, USA) supplemented with $10 \%$ albumin dextrose catalase $(5 \%$ albumin, $2 \% D$-glucose, $0.004 \%$ catalase and $0.85 \%$ sodium chloride), $0.2 \%$ glycerol and $0.05 \%$ Tween 80 .

Isolation of Mycobacterial Genomic DNA

Genomic DNA was isolated from 1.5-ml culture of $M$. tuberculosis H37Rv according to standard procedures [14]. 


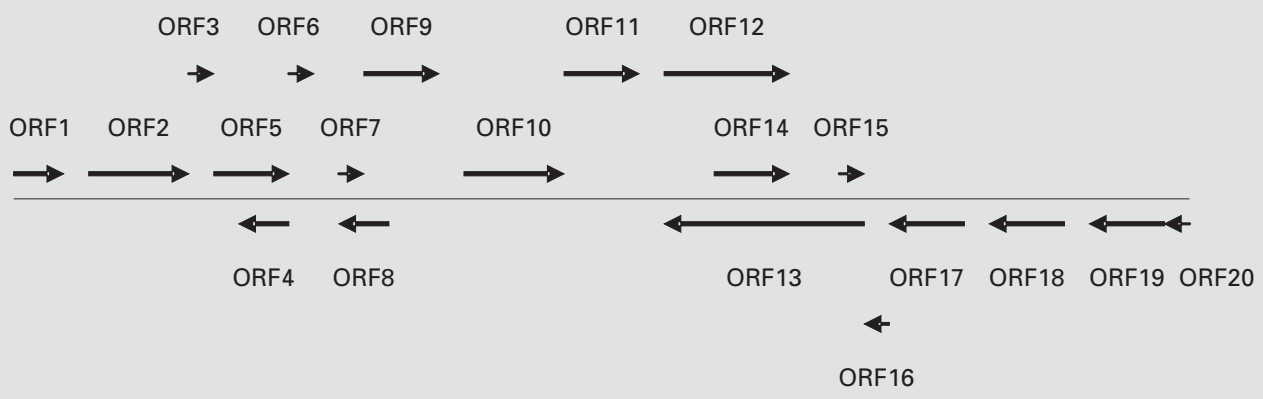

Fig. 1. ORFs in RD1 predicted by Robertson and Thole [1]. The arrows indicate orientation of expression of each ORF (right arrows for sense and left arrows complementary strand of DNA) as well as their relative size.

\section{Oligonucleotide Primers}

For each of the predicted ORFs in RD1, a pair of forward $(\mathrm{F})$ and reverse $(\mathrm{R})$ oligonucleotides primers were designed to amplify full-length genes in PCR. The primer sequences for each ORF were as follows:

ORF2F: 5'-AAT CGG ATC CAT GAC TGC TGA ACC GGA AGT-3' ORF2R: 5'-CTA TCT CGA GTC TTA ACC GGC GCT TGG GGG-3' ORF3F: 5'-AAT CGG ATC CAT GGA AAA AAT GTC ACA TGA-3' ORF3R: 5'-ACA GGA ATT CGG CCT ATT CGG CGA AGA AGA-3' ORF4F: 5' -GTG CGG GTC AAC GAC CCA CCT GCG CCA GGT-3' ORF4R: 5' -CTA CCA GGC CGA GAC CGC GGT TAA CAC GCT-3' ORF5F: 5'-AAT CGG ATC CAT GCT GTG GCA CGC AAT GCC-3' ORF5R: 5'-ACA GGA ATT CTC ACC AGT CGT CCT CTT CGT-3' ORF6F: 5'-AAT CGG ATC CAT GGC AGA GAT GAA GAC CGA-3' ORF6R: 5'-ACA GGA ATT CTC AGA AGC CCA TTT GCG AGG-3' ORF7F: 5'-AAT CGG ATC CAT GAC AGA GCA GCA GTG GAA-3' ORF7R: 5'-ACA GGA ATT CCT ATG CGA ACA TCC CAG TGA-3' ORF8F: 5'-GTG GGT GCA GGT CCG GCG ATG GGC ATC GGA-3' ORF8R: 5'-CTA CGA CAA GCT CTT CCG GCC GCA CGA AGG-3' ORF9F: 5'-GAT GGA ATT CCG TGA AGA AGG TGA AGC CCC-3' ORF9R: 5'-ATA TCC CGG GTC AAC GAC GTC CAG CCC TCT-3' ORF10F: 5'-TTG AGC GCA CCT GCT GTT GCT GGT CCT ACC-3' ORF10R: 5'-CCC AAG CTT TCA GAA CCG GAT ATT GCG GAC-3' ORF11F: 5'-CGC GGA TCC ATG GCT GAA CCG TTG GCC GTC-3' ORF11R: 5'-CCC AAG CTT TCA CAA CGT TGT GGT TGT TGA-3' ORF12F: 5'-C GAG CTC GTG GGC AGC GTA GGC CCG GAA-3' ORF12R: 5'-CCC AAG CTT TCA TTG GTC ACG GCG ACG CAT-3' ORF13R: 5'-C GAG CTC ATG AGT ATT ACC AGG CCG ACG-3' ORF13F: 5'-CCC AAG CTT TCA GCA TGC GGC GGC CAG GGC-3' ORF14F: 5'-CGC GGA TCC GTG CTC GGT GCC GCC GCC TTG-3' ORF14R: 5'-CCC AAG CTT TCA GCA GAA GTC GCC GCC ACC-3' ORF15F: 5'-C GAG CTC GTG GCC TTT CTG CTG GCG GCA-3' ORF15R: 5'-CCC AAG CTT TCA ACG GGT TAC TGC GAA TAC-3'

For ORFs 2, 9, 10 and 12 the following internal reverse (IR) primers were designed to be used with the corresponding forward primers in semi-nested PCR:

ORF2IR: 5'-GCC GCC ACC TAG GTC GAT GCA ATA GAA CTG-3' ORF9IR: 5'-GGC CGG TTC GGG TCC GGC GAT GGG CAT GGG-3' ORF10IR: 5'-GAC CAA CGG TCG GTA GCG CTC GGT GCG ACT-3' ORF12IR: 5'-GCC AGT TCG GAT CCC GGT GTG GCC AAG ATT-3'
Isolation of Total Mycobacterial RNA and cDNA Synthesis

Total nucleic acids were isolated from culture-grown $M$. tuberculosis H37Rv using MasterPure RNA purification kit (Epicenter Technologies, USA) according to the manufacturer's instructions. Total nucleic acids were precipitated with isopropanol and washed with $70 \%$ ethanol. To obtain DNA-free RNA, the suspension was treated with two units of DNAse (Gibco-BRL, USA) for $30 \mathrm{~min}$ at $37^{\circ} \mathrm{C}$. The enzyme was then inactivated at $75^{\circ} \mathrm{C}$ for $5 \mathrm{~min}$.

The isolated RNA was used to synthesize first-strand cDNA using first-strand cDNA synthesis kit (Pharmacia, USA) according to the manufacturer's instructions. In brief, the RNA solution was heated at $65^{\circ} \mathrm{C}$ for $10 \mathrm{~min}$ and then chilled on ice. Bulk first-strand cDNA reaction mix was added along with $1 \mu \mathrm{L}$ DT solution and $1 \mu \mathrm{l}$ Not $\mathrm{I}-\mathrm{d}(\mathrm{T})_{18}$ primer and pd $(\mathrm{N})_{6}$ primers in separate reaction tubes. An additional reaction mix was prepared for each RD1 ORF using ORF-specific forward primer. The mixtures were incubated at $37^{\circ} \mathrm{C}$ for $1 \mathrm{~h}$.

The isolation of DNA, RNA, and synthesis of cDNA were confirmed by amplification of a 245-bp target DNA from IS6110 sequence by using forward and reverse primers HM1 and HM2, respectively [14]. The amplification of this DNA fragment proved to be invariably positive with genomic DNA and negative with RNA. Only those cDNA preparations which showed positive HM1/HM2 RT-PCR products were used; otherwise, samples were discarded.

\section{Amplification of Genomic DNA and cDNA PCR}

Standard PCRs for amplification of genomic DNA and cDNA were performed as described previously [14]. In brief, PCR mixtures $(50 \mu \mathrm{l})$ consisted of $1 \times$ Gold Taq DNA polymerase buffer, $200 \mu M$ deoxynucleotide triphosphates, M. tuberculosis H37Rv genomic DNA (100 ng) or cDNA, 25 pmol of forward and reverse primers and $1 \mathrm{U}$ Gold Taq DNA polymerase (Applied Biosystems, USA). The reaction mixtures were heated at $95^{\circ} \mathrm{C}$ for $5 \mathrm{~min}$ in a thermal cycler (Perkin Elmer System 9600, USA), and then PCR was run for 30 cycles (denaturation at $94^{\circ} \mathrm{C}$ for $1 \mathrm{~min}$, annealing at $60^{\circ} \mathrm{C}$ for $1 \mathrm{~min}$ and extension at $72^{\circ} \mathrm{C}$ for $2 \mathrm{~min}$ ). At the end of the 30 th cycle, the mixture was held at $72^{\circ} \mathrm{C}$ for $10 \mathrm{~min}$. 

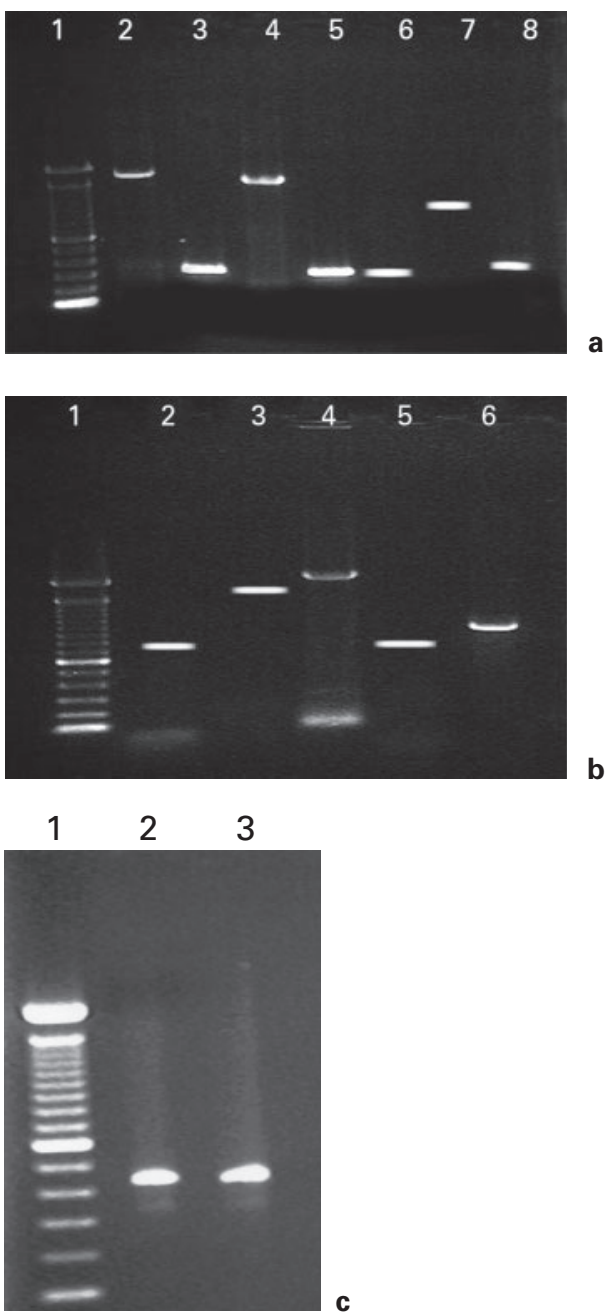

Fig. 2. PCR amplification of RD1 ORFs from genomic DNA of M. tuberculosis H37Rv. Genomic DNA isolated from M. tuberculosis $\mathrm{H} 37 \mathrm{Rv}$ were amplified in standard PCR in the presence of forward and reverse primers corresponding to each RD1 ORF. The amplified DNA were analyzed by agarose gel electrophoresis. a DNA corresponding to ORF2 (1.8 kb, lane 2$)$, ORF3 (0.3 kb, lane $3)$, ORF10 (1.7 kb, lane 4) and ORF15 (0.3 kb, lane 5) were amplified using standard reaction mixtures described in Materials and Methods. The amplification of ORF3 (0.3 kb, lane 6), ORF5 (1.1 kb, lane 7) and ORF6 (0.3 kb, lane 8) required addition of 2\% DMSO in the reaction mixture. Lane 1: 100-bp DNA ladder. b DNA corresponding to ORF9 (0.9-kb DNA amplified with forward internal primer, lane 6) was amplified using standard reaction mixture described in Materials and Methods. The amplification of ORF11 $(0.8 \mathrm{~kb}$, lane 2$)$ required addition of $4 \% \mathrm{DMSO}$, and the amplification of ORF12 (1.7 kb, lane 3), ORF13 (2.2 kb, lane 4) and ORF14 $(0.8 \mathrm{~kb}$, lane 5$)$ required addition of $8 \% \mathrm{DMSO}$ to the reaction mixture. Lane 1: 100-bp DNA ladder. c DNA corresponding to ORF4 $(0.4 \mathrm{~kb}$, lane 2$)$ was amplified using standard reaction mixture described in Materials and Methods. Amplification of ORF8 (0.4 kb, lane 3 ) required addition of $4 \%$ DMSO to the reaction mixture. Lane 1: 100-bp DNA ladder.
Every experiment with cDNA included controls for the corresponding ORF using water (negative control), RNA (negative control), and M. tuberculosis genomic DNA (positive control) as templates. The PCR products were resolved by agarose gel electrophoresis using standard procedures [14].

For ORFs not showing a visible band of specific size by standard PCR, semi-nested PCR was performed using $1 \mu l$ of the standard PCR product as a template, along with sequence-specific forward internal primer and the reverse primer corresponding to the respective ORF. Other materials and methods remained same as described above for standard PCR.

\section{Sequencing of RT-PCR Products}

The products of RT-PCR were sequenced for identity verification using standard procedures [13]. In brief, the amplified DNA were purified using QIA quick PCR purification kit (QIAGEN, USA) and reamplified using CEQ DTCS quick start kit (Beckman Coulter, USA) according to the manufacturer's instructions. DNA was concentrated by ethanol precipitation and sequenced using CEQ 8000 Genetic Analysis System (Beckman Coulter). The nucleotide sequences obtained for each PCR product were analyzed for identity by manual comparison with the known sequences of the corresponding ORF and BLAST search (www.ncbi.nlm.nih. gov/blast/).

\section{Results}

\section{Standardization of M. tuberculosis H37Rv Culture for RT-PCR}

Before attempting to perform experiments to demonstrate the expression of RD1 ORFs by RT-PCR, the conditions for RT-PCR, with respect to the duration of culture and number of $M$. tuberculosis $\mathrm{H} 37 \mathrm{Rv}$, were optimized by using primers HM1/HM2. These standardization experiments showed that best RT-PCR results were obtained with $M$. tuberculosis cultures grown for 6-8 weeks containing about $5 \times 10^{8} \mathrm{CFU} / \mathrm{ml}$ (data not shown).

\section{Optimization of Reaction Conditions for the Amplification of RDI ORFs from the Genomic DNA of M. tuberculosis $H 37 R v$}

We have previously shown that PCR amplification of some of the ORFs of $M$. tuberculosis requires addition of DMSO and formamide to the reaction mixture [13]. Therefore, to optimize the conditions for PCR amplification of RD1 ORFs from cDNA, reaction conditions were optimized for the amplification of each ORF DNA using genomic DNA of $M$. tuberculosis as a template. The results showed that ORFs 2, 4, 7, 9, 10 and 15 were amplified using the standard reaction mixture described in the materials and methods section, whereas the amplification of other ORFs required addition of 2-8\% DMSO (fig. 2). 
Table 2. Amplification of RD1 ORFs in PCR with cDNA synthesized from RNA isolated from M. tuberculosis

\begin{tabular}{|c|c|c|c|c|}
\hline ORF & Primers ${ }^{1}$ yielding PCR-amplifiable cDNA & $\begin{array}{l}\text { RT-PCR type giving } \\
\text { positive amplification }\end{array}$ & $\begin{array}{l}\text { Size of the amplified } \\
\text { RT-PCR product, kb }\end{array}$ & $\begin{array}{l}\text { Identity of RT-PCR product } \\
\text { upon DNA sequencing }\end{array}$ \\
\hline 2 & $\operatorname{Pd}(\mathrm{N})_{6}$ & semi-nested $^{2}$ & 0.4 & Rv3871, ORF2 \\
\hline 4 & Not $\mathrm{I}-\mathrm{d}(\mathrm{T})_{18}$ & standard & 0.4 & ORF4 \\
\hline 5 & $\operatorname{Pd}(\mathrm{N})_{6}$, Not $\mathrm{I}-\mathrm{d}(\mathrm{T})_{18}$, specific primer & standard & 1.1 & Rv3873, ORF5 \\
\hline 6 & $\operatorname{Pd}(\mathrm{N})_{6}$, Not $\mathrm{I}-\mathrm{d}(\mathrm{T})_{18}$, specific primer & standard & 0.3 & Rv3874, ORF6 \\
\hline 8 & Not $\mathrm{I}-\mathrm{d}(\mathrm{T})_{18}$ & standard & 0.4 & ORF8 \\
\hline 9 & specific primer & semi-nested & 0.3 & Rv3876, ORF9 \\
\hline 10 & none $^{3}$ & none & none & not applicable \\
\hline 11 & specific primer & standard & 0.8 & Rv3878, ORF11 \\
\hline 12 & Not $\mathrm{I}-\mathrm{d}(\mathrm{T})_{18}$ & semi-nested & 0.3 & ORF12 \\
\hline 13 & $\operatorname{Pd}(\mathrm{N})_{6}$ & standard & 2.2 & Rv3879, ORF13 \\
\hline
\end{tabular}

${ }^{1}$ cDNA synthesis was attempted with general as well as ORF-specific forward primers; however, results are given only with those primers which gave positive PCR.

${ }^{2}$ Semi-nested PCR was attempted when standard PCR failed to amplify the desired products.

${ }^{3}$ ORF10 was not amplified with any of the three preparations of cDNA, which were synthesized using two general and one specific primers.

These optimized concentrations of DMSO were used while attempting to amplify the corresponding ORFs from cDNA preparations. The full-length ORF9 DNA segment $(2.0 \mathrm{~kb})$ was not amplified in standard PCR in the absence as well as in the presence of different concentrations of DMSO (data not shown); however, a smaller fragment of ORF9 $(0.9 \mathrm{~kb})$ was amplified using the standard reaction mixture (fig. 2b, lane 6).

\section{RT-PCR of RDI ORFs with RNA Isolated from}

M. tuberculosis

To determine the effect of general and specific primers on cDNA synthesis, cDNA was synthesized from isolated RNA of $M$. tuberculosis using general primers [Not $\mathrm{I}-\mathrm{d}(\mathrm{T})_{18}$ and $\mathrm{pd}(\mathrm{N})_{6}$ primers] included in the cDNA synthesis kit and ORF-specific forward primers. The cDNA preparations were used in standard and semi-nested PCR for ORFs not amplified in standard PCR to identify transcriptionally active ORFs of RD1. The RT-PCR results showed that ORF5, ORF6, ORF7 and ORF14 were amplified from cDNA preparations that were synthesized by using all three sets of primers, i.e. the two general [Not I-d $(\mathrm{T})_{18}$ and $\mathrm{pd}(\mathrm{N})_{6}$ primers] and one specific primer corresponding to each ORF. ORF2 and ORF13 were amplified only with $\mathrm{pd}(\mathrm{N})_{6}$. ORF3, ORF4, ORF8, ORF12 and ORF15 were amplified only with $N o t$ I-d(T) $)_{18}$. ORF9 and ORF11 were amplified only with ORF-specific primers. However, ORF10 was not amplified with any of the three preparations of cDNA (table 2; results of ORF14, ORF2, ORF3 and ORF9 are presented in figure $3 a, b, c$ and $d$, respectively).

\section{Sequencing of RT-PCR Products}

To confirm their identity, the RT-PCR products were sequenced as described in Materials and Methods. The manual comparison of the sequences as well as the BLAST searches confirmed their respective identities (table 2).

\section{Discussion}

Bioinformatics analysis of DNA regions is an effective tool to predict encoded genes in $M$. tuberculosis genome [12]. Various groups, however, have predicted varying numbers of ORFs in M. tuberculosis-specific segment of RD1 using different computer programs. Robertson and Thole used the GeneMark software and predicted the existence of 14 ORFs (ORF2-15; table 1). Mahairas et al. [4] annotated eight potential ORFs in the same region (ORFs 2, 5, 7, 9, 10, 11, 12 and 13 of Robertson and Thole; table 1). In the genome sequence of $M$. tuberculosis H37Rv, Cole et al. [12] annotated 9 ORFs in this re- 

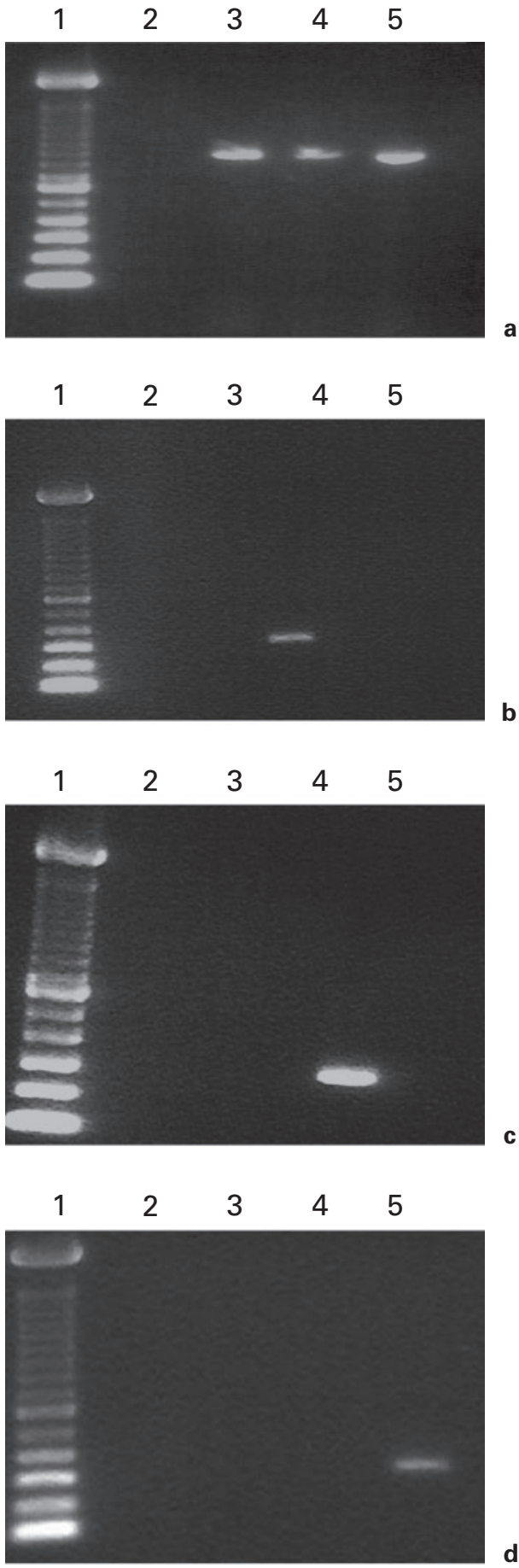

Fig. 3. Representative examples of RT-PCR results obtained with DNAse-treated RNA of $M$. tuberculosis using general and ORFspecific primers for cDNA synthesis. a ORF14 was amplified by standard PCR from cDNA synthesized using both of the general primers, i.e. $\operatorname{Pd}(\mathrm{N})_{6}$ and Not $\mathrm{I}-\mathrm{d}(\mathrm{T})_{18}$, as well as ORF-specific forward primer (lanes 3, 4 and 5, respectively, product at $0.8 \mathrm{~kb}$ ). Lane 2: PCR control for ORF14 with DNAse-treated RNA (negative control). Lane 1: 100-bp DNA ladder. b ORF2 was amplified by semi-nested PCR from cDNA synthesized using $\mathrm{Pd}(\mathrm{N})_{6}$ general gion (ORFs 2, 3, 5, 6, 7, 9, 10, 11, and 13 of Robertson and Thole, table 1). In total, Mahairas et al. [4] and Cole et al. [12] predicted 10 ORFs in the RD1 DNA segment, of which seven were common to both predictions, two were specific for Cole et al. [12] and one was predicted only by Mahairas et al. [4] (table 1). According to the analysis of Robertson and Thole, four extra ORFs (ORF4, 8,14 and 15 ) can be predicted in addition to the 10 ORFs which can be predicted by the other two groups (table 1, fig. 1). However, several of these predictions are only hypothetical (table 1) as the corresponding genes and/or proteins have not been shown to be expressed in M. tuberculosis. In this context, RT-PCR has previously been used to identify the genes that are actively transcribed during growth of the microorganisms [15].

To verify the bioinformatics predictions at the level of mRNA expression, we carried out the present study and included all 14 RD1 ORFs (ORF2-15) predicted by Robertson and Thole (fig. 1). Our results confirm that, except ORF10, all other predicted ORFs were expressed at the mRNA level in $M$. tuberculosis under in vitro growth in culture. Despite ORF10 being predicted by all the three analyses (ORF10 of Robertson and Thole, Rv3877 of Cole et al. [12] and ORF1E of Mahairas et al. [4]; table 1), failure to detect its expression by RT-PCR could be due to a very low copy number of its mRNA. Other reasons could be that ORF10 is expressed only in vivo or its expression is under control of other factors in vivo. Examples of such genes that are expressed in vivo but not in vitro cultures include Ag85A [15].

Among the ORFs predicted only by Robertson and Thole are ORF4, ORF8, ORF14 and ORF15, and this study demonstrate that all of these were expressed in M. tuberculosis at the mRNA level. The expression of

primer (lane 4, product at $0.4 \mathrm{~kb}$ ). ORF2 was not amplified from cDNA synthesized using the other general primer Not I-d(T) ${ }_{18}$ (lane 3) or specific primer (lane 5). Lane 2: PCR control for ORF2 with DNAse-treated RNA (negative control). Lane 1: 100-bp DNA ladder. c ORF3 was amplified by standard PCR from cDNA synthesized using Not $\mathrm{I}-\mathrm{d}(\mathrm{T})_{18}$ general primer (lane 4, product at $0.3 \mathrm{~kb}$ ). ORF3 was not amplified from cDNA synthesized using the other general primer $\operatorname{Pd}(\mathrm{N})_{6}$ (lane 3) or specific primer (lane 5). Lane 2: PCR control for ORF3 with DNAse-treated RNA (negative control). Lane 1: 100-bp DNA ladder. d ORF9 was amplified by seminested PCR from cDNA synthesized using ORF9-specific forward primer (lane 5, product at $0.3 \mathrm{~kb}$ ). ORF9 was not amplified from cDNA synthesized using the general primers $\mathrm{Pd}(\mathrm{N})_{6}$ (lane 3 ) or Not I-d(T) 18 (lane 4). Lane 2: PCR control for ORF9 with DNAse-treated RNA (negative control). Lane 1: 100-bp DNA ladder. 
ORF14 in $M$. tuberculosis has been determined at the protein level by using anti-ORF14 antibodies raised in mice against recombinant ORF14 protein [unpubl. results]. The antibodies reacted with a single protein band in western immunoblots of the culture filtrate of $M$. tuberculosis, which corresponded to the expected size of the protein [unpubl. results]. Moreover, antibodies in sera from TB patients, but not from BCG-vaccinated healthy donors, reacted with the recombinant protein in western immunoblots [13], which further confirmed the expression of ORF14 in M. tuberculosis.

In addition to confirming the expression of the predicted RD1 ORFs, this work shows that, for RT-PCR, it is not sufficient to synthesize first-strand cDNA using only one type of primer, either general or specific. Some ORFs were successfully amplified from first-strand cDNA synthesized with all the primers, both general and specific; whereas others required either general or specific primers for effective cDNA synthesis. ORF9 and ORF11 were amplified only with ORF-specific primers, and not with general ones. Such results suggest that the corresponding mRNAs could be less abundant than the others. The differential effect of primers on the synthesis of firststrand cDNA has also been studied by other researchers and was proven to be considerable when determining the expression of genes at mRNA level [16]. In addition, the size of the ORFs presented a factor for the successful amplification of full length ORFs. In general, ORFs $\leq 0.5 \mathrm{~kb}$ were amplified efficiently in the first round of standard PCR, otherwise re-amplification in semi-nested PCR using internal primers was necessary to obtain the desired product [15]. However, in this study several ORFs $\geq 0.5 \mathrm{~kb}$, ORF5 (1.1 kb), ORF11 (0.8 kb), ORF14(0.8 kb) and ORF13 (2.2 kb) were amplified by standard PCR indicating that the mRNA of these ORFs are abundant enough in total RNA to be detected directly. Finally, both size and abundance of mRNA play a coupled effect in the detection of the corresponding ORFs by RT-PCR.

The density and age of the cultures of $M$. tuberculosis $\mathrm{H} 37 \mathrm{Rv}$ were additional factors to standardize the products of RT-PCR. Detectable levels of mRNA and hence successful cDNA synthesis were possible when the culture was grown for 6-8 weeks or until it reached a density of $5 \times 10^{8} \mathrm{CFU} / \mathrm{ml}$. These results are also consistent with the observations reported previously [15].

\section{Conclusion}

This study demonstrated that RT-PCR is an effective tool to confirm the expression of genes predicted in the M. tuberculosis-specific genomic segment of RD1. However, reaction conditions and primers required for optimal cDNA synthesis and PCR amplification should be standardized.

\section{Acknowledgments}

The study was supported by Kuwait University Research Administration grants MI01/01, MI02/02, and the Department of Microbiology, Faculty of Medicine, Kuwait University.

\section{References}

1 Mustafa AS: Biotechnology in the development of new vaccines and diagnostic reagents against tuberculosis. Curr Pharm Biotechnol 2001;2:157-173.

2 Mustafa AS: Mycobacterial gene cloning and expression, comparative genomics, bioinformatics and proteomics in relation to the development of new vaccines and diagnostic reagents. Med Princ Pract 2005; 14:27-34.

3 Mustafa AS: Progress towards the development of new anti-tuberculosis vaccines; in Smithe LC (ed): Focus on Tuberculosis Research. New York, Nova, 2005, pp 47-76.

-4 Mahairas GG, Sabo PJ, Hickey MJ, Singh DC, Stover K: Molecular analysis of genetic differences between Mycobacterium bovis BCG and virulent $M$. bovis. J Bacteriol 1996;178:12741282.
\$5 Mustafa AS, Amoudy HA, Wiker HG, Abal AT, Ravn P, Oftung F, Andersen P: Comparison of antigen specific T-cell responses of tuberculosis patients using complex or single antigens of Mycobacterium tuberculosis. Scand J Immunol 1998;48:535-543.

6 Skjot RLV, Oettinger T, Rosenkrands I, Ravn P, Brock I, Jacobsen S, Andersen P: Comparative evaluation of low-molecular-mass proteins from Mycobacterium tuberculosis identifies members of the ESAT- 6 family as immunodominant T-cell antigens. Infect Immun 2000; 68:214-220.

7 Arend SM, Andersen P, van Meijgaarden KE, Skjot RL, Subronto YW, van Dissel JT, Ottenhoff THM: Detection of active tuberculosis infection by $T$ cell responses to early-secreted antigenic target 6-kDa protein and culture filtrate protein 10. J Infect Dis 2000;181:1850-1854.
8 Liu XQ, Dosanjh D, Varia H, Ewer K, Cokle P, Pasvol G, Lalvani A: Evaluation of T-cell responses to novel RD1- and RD2-encoded Mycobacterium tuberculosis gene products for specific detection of human tuberculosis infection. Infect Immun 2004;75:2574-2581.

9 Mustafa AS, Oftung F, Amoudy HA, Madi NM, Abal AT, Shaban F, Rosen Krands I, Andersen P: Multiple epitopes from the Mycobacterium tuberculosis ESAT-6 antigen are recognized by antigen-specific human $\mathrm{T}$ cell lines. Clin Infect Dis 2000;30(suppl 3):S201-S205.

10 Mustafa AS, Shaban FA, Al-Attiyah R, Abal AT, El-Shamy AM, Andersen P, Oftung F: Human Th1 cell lines recognize the Mycobacterium tuberculosis ESAT-6 antigen and its peptides in association with frequently expressed HLA class II molecules. Scand J Immunol 2003; $57: 125-134$. 
11 Berthet FX, Rasmussen PB, Rosenkrands I, Andersen P, Gicquel B: A Mycobacterium tuberculosis operon encoding ESAT-6 and a novel low-molecular-mass culture filtrate protein (CFP-10). Microbiology 1998;144:31953203.

$\checkmark 12$ Cole ST, Brosch R, Parkhill J, Garnier T, Churcher C, Harris D, Gordon SV, Eiglemeier K, Gas S, Barry III CE, Tekaia F, Badcock K, Basham D, Brown D, Cillingworth T, Connor R, Davies R, Devlin K, Feltwell T, Gentles S, Hamlin N, Holroyd S, Hornsby T, Jagels K, Barrell BG, et al: Deciphering the biology of Mycobacterium tuberculosis from the complete genome sequence. Nature 1998;393:537-544.
3 Ahmad S, Amoudy HA, Thole JER, Young DB, Mustafa AS: Identification of a novel protein antigen encoded by a Mycobacterium tuberculosis specific RD1 region gene. Scand J Immunol 1999;49:515-522.

14 Mustafa AS, Chugh TD, Abal AT: Polymerase chain reaction targeting of single- and multiple-copy genes of mycobacteria in the diagnosis of tuberculosis. Nutrition 1999;11(suppl):665-669.
15 Mariani F, Cappelli G, Riccardi G, Colizzi V: Mycobacterium tuberculosis H37Rv comparative gene-expression analysis in synthetic medium and human macrophage. Gene 2000; 253:281-291.

16 Rivera-Marrero CA, Burroughs MA, Masse RA, Vannberg FO, Leimbach DL, Roman J, Murtagh JJ Jr: Identification of genes differentially expressed in Mycobacterium tuberculosis by differential display PCR. Microb Pathog 1998;25:307-316.

17 Mustafa AS: Development of new vaccines and diagnostic reagents against tuberculosis. Mol Immunol 2002;39:113-119. 